\title{
YINGSHAO: A FLEXIBLE DATA COLLECTION AND MANAGEMENT PLATFORM FOR CHINA'S HERITAGE SITES
}

\author{
B. $\mathrm{Li}^{1}$, W. Zhao ${ }^{2}$, P. Gu${ }^{2}$, G. Zhang ${ }^{1}$ \\ ${ }^{1}$ Beijing Tsinghua Tongheng Urban Planning \& Design Institute, China - (liboying, zhanggong)@thupdi.com \\ ${ }^{2}$ Beijing CityDNA Technology Co.,Ltd, China - (wenhuazhao, peiqingu)@citydnatech.com
}

KEY WORDS: Heritage Site, Data Collection, Full Lifecycle Management, WebGIS, Spatio-temporal Database.

\begin{abstract}
:
The advancement of geoinformatics technologies promotes national-level attention to heritage inventories and digital platforms. The management of heritage sites requires a more efficient and flexible collection methodology to collect GIS data and support extended applications. This paper discusses the system design and application of Yingshao platform, a more flexible and efficient data collection platform for Chinese heritage sites and full lifecycle management. It applis a framework of WebGIS, MobileGIS and WebGL and adopts a data storage scheme of MySQL and MangoDB. Based on the advanced system architecture, the platform has formed better solutions: (1) establishing a standard and cooperative workflow; (2) integrating diverse data sources; (3) building a flexible geospatial database with a time dimension; (4) ensuring data security and safety. In the applications in China's heritage sites, it significantly improves the efficiency and flexibility during collection. Meanwhile, the collected data could well support management scenarios. We believe that the platform could become an effective and flexible data collection and management tool for China's heritage sites, and it has the potential to become the foundation for full lifecycle management.
\end{abstract}

\section{INTRODUCTION}

In the 21 st century, "protection and utilization of heritage" has become a consensus to promote the sustainable development of humanity. In 2011, UNESCO passed the "HUL (Historic Urban Landscape) Recommendation" to provide a framework to balance protection, development and sustainable management. HUL recommends a mechanism to combine public participation, professional planning, management mechanism and financial tools, which are important methods for the renewal and management of heritage sites.

Under the framework of sustainable management, a digital management platform is an effective way to protect and develop heritage sites. Worldwide experiences have proved that establishing a standard heritage inventory (Myers, 2016) and manage heritages (Xiao et al., 2018) can promote economic development and improve the living environment. In recent years, China has issued significant policies to promote effective protection and full lifecycle management of heritage sites, emphasizing the necessity of digitization. Related pilot projects show that digital archives and management platforms (Qu et al., 2019) can quickly improve the management level, primarily supporting monitoring and repairs of historic buildings.

With the development of digital technology, data collection has become the foundation for heritage sites' full life cycle management. However, data collection scenarios are diverse. China's heritage sites have numerous architectural and natural heritage, such as immovable cultural relics, historical buildings, and historical environmental elements. Also, there are various tasks in management: protection and inspection, planning and design, repair and construction, operation and display, monitoring and evaluation. Confronted with complex scenarios throughout full lifecycle management, managers are urging a flexible data collection system to support extended applications.
This paper mainly introduces Yingshao data collection and management platform for China's heritage sites. At first, we review the existing methodologies and platforms of data collection for heritage sites, mainly focus on standardization and flexibility. Based on the analysis results of the demands in the third section, the fourth section illustrates the system design and emphasizes the innovations. Then, this paper presents the application case studies of Yingshao platform. These applications demonstrate in detail how Yingshao platform can improve the data collection process with the merits of flexibility and effectiveness. Conclusion and possible directions of future development are discussed in the final section.

\section{RELATED RESEARCH AND PLATFORMS}

\subsection{Collection Technologies and Full Lifecycle}

Today's technologies are not fully utilized in heritage sites' full lifecycle management. In the past ten years, using geoinformatics technologies such as crowdsourcing and laser scanning are the major methodology to collect heritage databases, especially for heritage buildings. Although these technologies have been advanced and popular, they only support specific scenarios, such as monitoring, restoration and representation.

\subsection{Inventories and Collection Standards}

Data standards and flexible data storage methods are the fundamentals for integrated management. However, existing collection methodologies lack such information standards or a comprehensive throughout design that can support complicated and variated business details. Since a long-term absence of data standards, creating a comprehensive heritage inventory by simply merging spatial data from diverse sources is challenging. Even though there are several successful experiences in the Middle East, North Africa and Asia Minor (Zerbini, 2018; Aspöck, Masur, 2015), these standards are not appropriate for 
China because of the differences in heritage types and management mechanisms.

\subsection{Existing Collection Platforms}

Related data collection platforms almost apply a stabilized data structure and cannot essentially improve efficiency and quality. Geographic information systems have already been used in heritage data collection and management, integrating laser scan data or crowdsourcing data. For instance, CityGML (Dore, 2012) and Agata platform (Soler et al., 2017) integrate 3D Laser Scanning and photographic surveys. These platforms have limitations in the collected attributes and users. On the other hand, public participation GIS platforms such as Lost Culture Heritage platform (Stathopouloua et al., 2015) and Share Our Cultural Heritage (SOCH) (Dhonju et al., 2018) are designed for GIS data and related photo files. Though Arches platform (Myers et al, 2012) can be customized for different scenarios, users can't quickly perceive and evaluate heritage information. To sum, these WebGIS platforms have low efficiency in on-site data collection and are more suitable for management.

In China, available collection tools are mainly designed for general land surveys. Therefore, an ideal platform should make progress upon existing system architecture to support complex data collection scenarios to form a solid foundation for full lifecycle management.

\section{DEMAND ANALYSIS}

In the context of data-driven management and algorithm-driven decision-making, various scenarios related to full lifecycle management require flexible and professional databases.

However, there is currently no data collection platform designed rereferring to the characteristics of Chinese heritage sites, resulting in low quality of collected data and insufficient information. These data fail to participate in management scenarios. At the same time, no data collection platform can integrate and display multi-temporal databases, such as oblique photogrammetry models and remote sensing images. These databases provide extra on-site assessment references, which significantly improve the efficiency and accuracy of collection.

\subsection{Combining Collection with Management Needs}

Under the national and local regulations and norms, the organizational structure and management mechanism are diverse in different heritage sites. Therefore, a standard data template is necessary to meet management needs.

\subsection{Data Integration and Collaborative Environment}

Many types of data are involved in the full lifecycle management, such as vector GIS data and management-related information, the measured drawings, orthophotos and oblique photogrammetry models, photos and other multimedia information. Integrate multi-source data can more effectively support protection management and provide data mining and artificial intelligence algorithm development in the future.

At the same time, since the data collection process will produce a large number of operations on the existing database, data synchronization can effectively avoid information loss and repeated operations.

\subsection{Full Lifecycle Database for Stakeholders}

Adding a time dimension to the database will greatly promote effective supervision and precise services in the future. The protection elements of heritage sites are numerous and widely distributed. Integrating the dispersed data could promote the level of supervision. Along particular heritage element's lifecycle, various stakeholders have marked different information during different stage, from design and engineering to monitoring and evaluation. A database with a time dimension can provide more comprehensive information and improve the service level of the heritage site.

With regards to above demands and existing data collecting platforms, heritage sites are calling for following upgrades: a flexible and expert collection results, a synchronized working environment and an integrated database with time dimension consideration.

\section{SYSTEM DESIGN AND INNOVATION}

Since these demands need to be solved systematically, we designed Yingshao data collection and management platform for China's heritage sites. Upon previous systems, Yingshao platform solves limitations by applying advanced framework and efficient data storage schema.

\subsection{System Design}

The entire system design (Figure 1.) could be divided into three main layers, basic infrastructure layer, information resource layer and application layer. At the same time, support system consists two systems, which are unified user system and standard specifications.

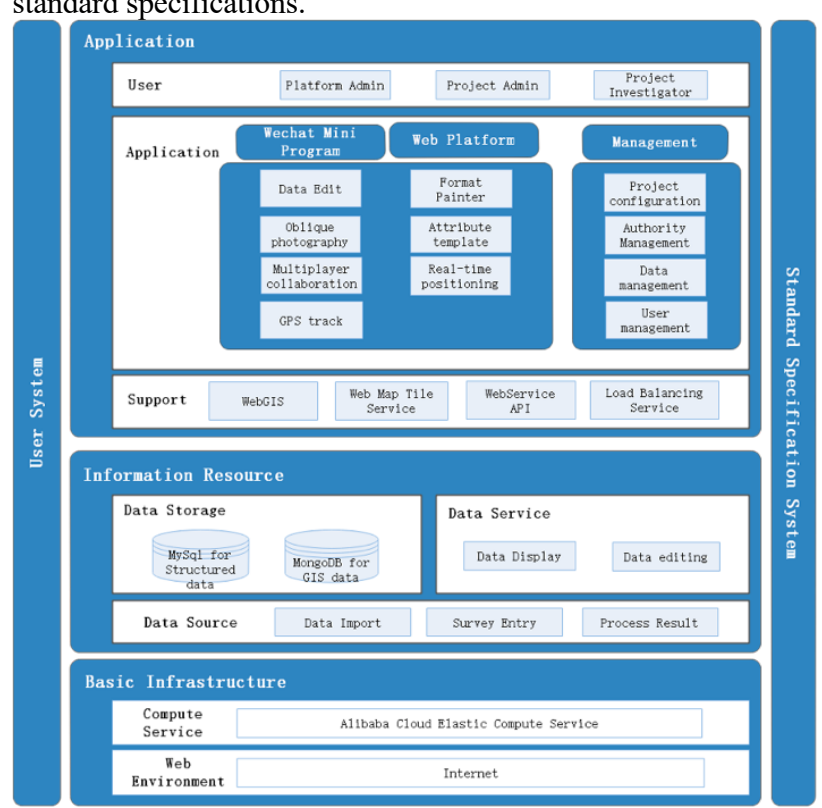

Figure 1. The System Architecture of Yingshao Platform.

4.1.1 Basic Infrastructure Layer: The basic infrastructure layer is to plan and design the construction of information infrastructure such as computing and storage, network servers, and provide stable basic support for the operation of the system. The entire system is deployed on the Alibaba Cloud platform and can be accessed via the Internet. 
4.1.2 Information Resource Layer: The information resource layer collects internal and external data through unified planning, uses the interface specifications for data sharing, exchange, and extraction as the standard, uses unified standards for processing and storage of data from different sources, and provides data support for the application layer.

1. System data sources include basic data import, survey data entry and business result processing data.

2. Data storage applies relational database MySQL and non-relational database MongoDB according to data format requirements. MySQL database is mainly used to store structured data such as survey questionnaire data, user data, and system management data. MongoDB is mainly used to store geographic information spatial data. After logical inspection and cleaning of data from different sources, unified standards are adopted for processing and storage.

3. The data service layer mainly provides the export and entrance of data exchange. In addition, provide data display and data editing functions.

4.1.3 Application Support Layer: The application support level realizes the support for business applications, including WebGIS services, Web map tile services, load balancing services and Web Service.

4.1.4 Application Layer: This system comprises two subsystems, data collecting front-end and backstage management system.

1. The front-end: It includes two client-ends, WeChat mini-program and desktop browser (Figure 2 and 3). WeChat mini-program makes on-site survey portable and convenient, while the desktop browser web platform allows intensive operations in different scenarios. Data collecting front-end allows data collectors to enhance the efficiency and accuracy in different collecting scenarios. Based on the system-level of data synchronization and integration, users could view and edit multi-dimensional data. Its functional modules are represented in the following contents.

(1) Data edit: Users could add, delete, modify the spatial and attribute information of vector GIS data on different layers, as well as include photos.

(2) Data display: Users could view and hide different layers, including GIS vector data layers, remote sensing images, online base maps, orthophotos and oblique photogrammetry models. Based on one attribute of GIS data or the completion level of data collection, users could render the vector layers.

(3) Oblique photogrammetry model display: Users could overlay and display the oblique photogrammetry models.

(4) Multi-user collaboration: Every saved edit of GIS data will be updated online; in this way, data collectors can instantly understand the project's progress.

(5) GPS track: It is only used on WeChat mini-program. Users could record and view the GPS tracking through location positioning.

(6) Real-time positioning: It is only used on WeChat mini-program. Users can view the current position and direction pointer when the position positioning is turned on the mobile phone.

(7) Attribute format painter: Users could copy and paste one vector feature's attributes to the others nearby, which share the same attributes.

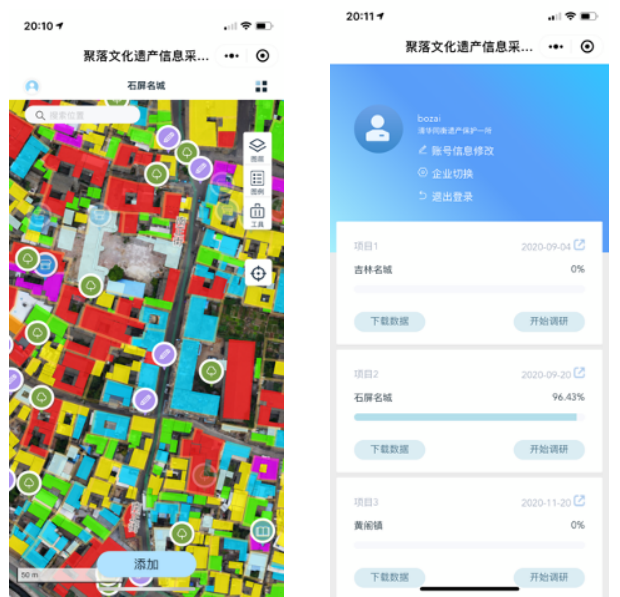

Figure 2. WeChat Mini-Program Front-end (Data Collection Interface on Left; Project-orientation Interface on Right), Example of Shiping Historic City.

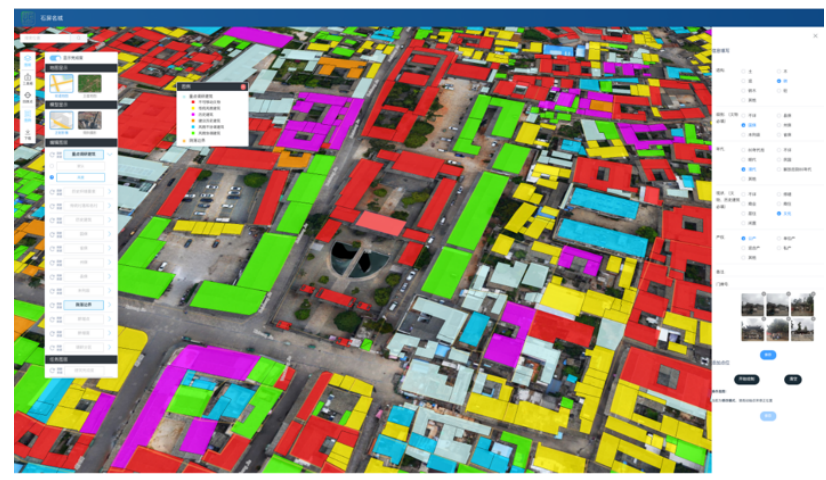

Figure 3. Desktop Browser Front-end, Example of Shiping Historic City.

2. Backstage management system: It allows users to customize the projects and user roles to meet (Figure 4,5 and 6). Based on the system-level of data standardization and security, users could upload and download specific data. Its functional modules are represented in the following contents.

(1) Project configuration: Organization administrators could add, delete and modify basic information of a data collection project, as well as start and close a project. Before a project, it provides the $\mathrm{QR}$ code and allows administrators to assign tasks. At the same time, project administrators could upload GIS data and modify layer attributes information, set up the online base map and remote sensing image, upload orthophoto and oblique photogrammetry models.

(2) Data template: It allows users to import and export the standard or custom templates. In this way, users could modify the GIS data's attribute information quickly and adequately.

(3) User and permission management: Organization and project administrators could add, delete and modify user roles and function permissions.

(4) Data management: Users could view and download the collected GIS data, with the format of ESRI Shapefile, GEOJSON or CSV. Photos are organized by compressed folders and sent to the user's email. 


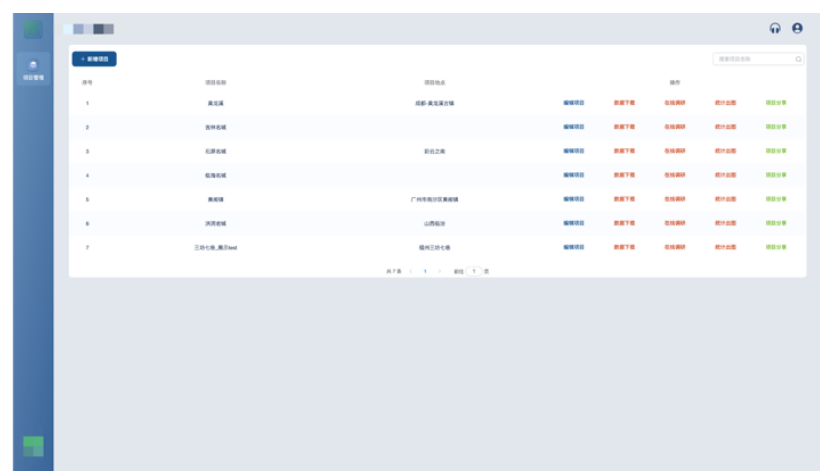

Figure 4. Project Management Page in Backstage Management System.

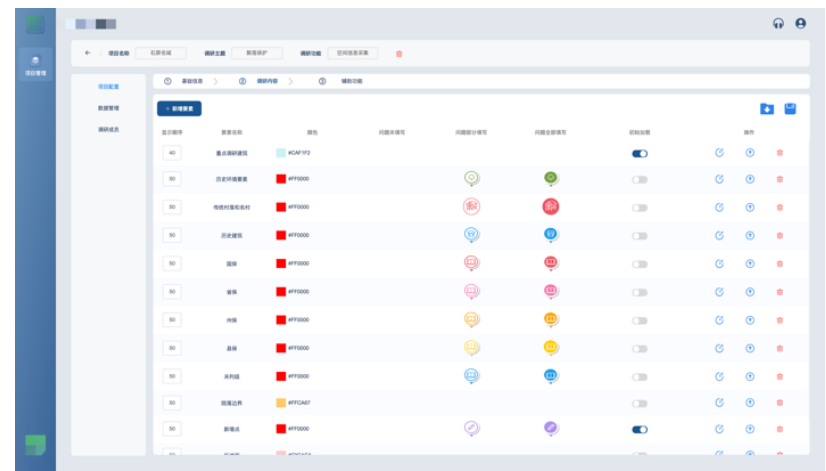

Figure 5. Resources Collecting Configuration Page in Backstage Management System.

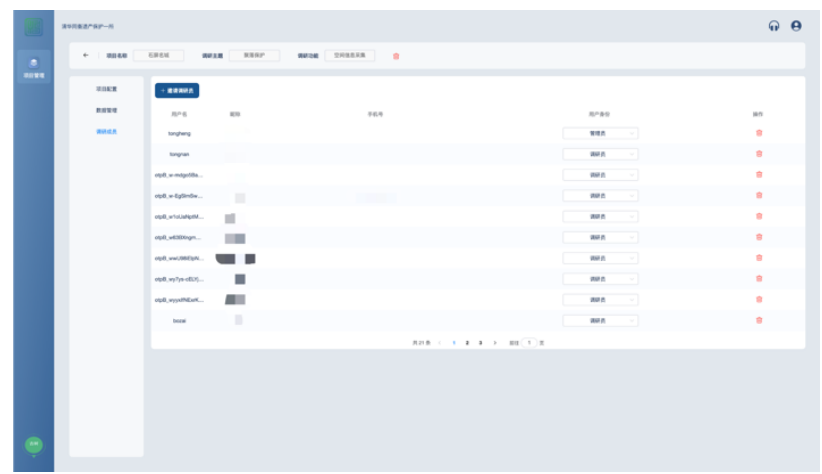

Figure 6. Collector Management Page in Backstage Management System.

4.1.5 User Roles and Permission System: A role-based permission system ensures operation safety and data security. Users are divided into four roles: organization administrators, organization members, project administrators and project data collectors. The system permission is divided into two parts: organization permission and project permission, which respectively manage the user's operation and data permission in the organization and project.

\subsubsection{Support system:}

1. Unified user system: Users can either enter the system through authorization on WeChat or use their mobile phone number to register in the backstage management system for data exchange.

2. Standards: The platform adopts the WGS84 coordinate system as the standard geospatial reference, which could make quick transformations with China Geodetic Coordinate System 2000. Also, it uses national and local standards to standardize the attribute fields.

\subsection{System Innovation}

To meet the needs of data collection in China's heritage sites, this system adopts an advanced system architecture and specific functional design. It innovates from the aspect of workflow and data flow, data structure and security.

\subsubsection{Establishing A Standard \& Cooperative Workflow:} The platform establishes a cooperative workflow on multiple client-ends. This synchronized working environment is paperless and well support collecting on a larger scope. Also, it applies a standard spatial reference and designs a data template module, which contributes to a standard workflow.

Data template is flexible and efficient (Figure 7 and 8). According to the standards, the user formulates attribute templates, including attributes fields and rendering methods. Then the user creates and uploads a template excel file. The platform will generate a data template and store it in the database. Simultaneously, similar projects can directly obtain the configuration by calling templates, avoiding rework and ensuring consistent data standards and visualization.

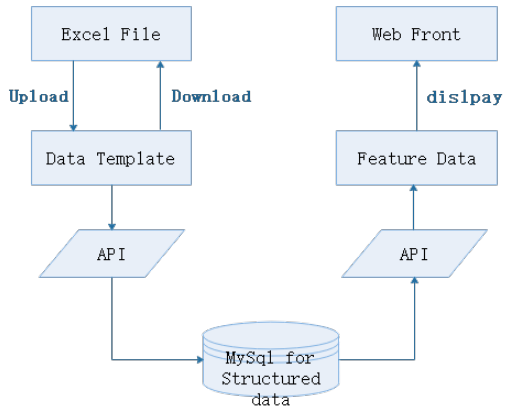

Figure 7. Diagram of how attribute templates work.

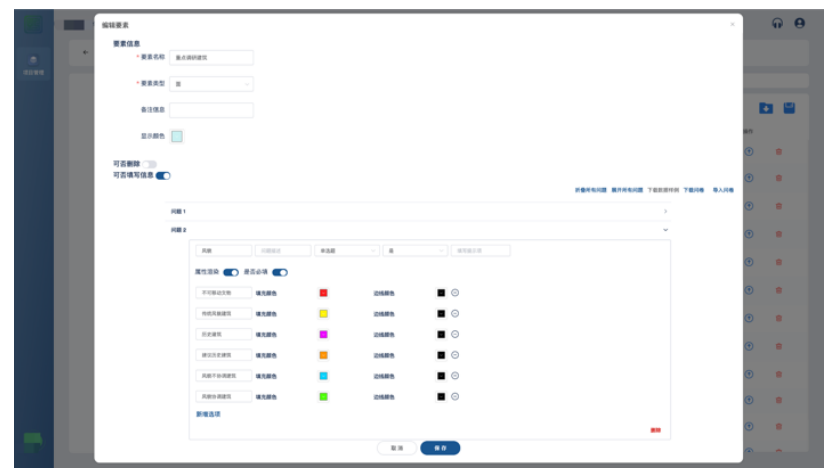

Figure 8. Data Template Module.

4.2.2 Integrating Diverse Data Sources: Under the need of integrating multi-source data, it applies an efficient data storage schema of MySQL and MongoDB to integrate structured data, GIS data, photos and file data related to projects. The complete dataflows are shown below (Figure 9).

1. Vector GIS data: GIS data is stored in the MongoDB unstructured database, while the attribute is in the MySQL structured database. These two parts are obtained through the interface service API, and GIS data is displayed on the client end.

2. Orthophoto \& oblique photogrammetry model: These data are stored in the OSS file storage system and published as Web Map Tile Service (WMTS) through 
GeoServer (Figure 10). The client-end obtains the map tiles in the form of pyramids through standard URLs for hierarchical display. WMTS uses a tile matrix set to represent the map tiles, displaying tiles of corresponding resolutions at different spatial scales and effectively ensuring the response display speed of data at various scales (Figure 11).

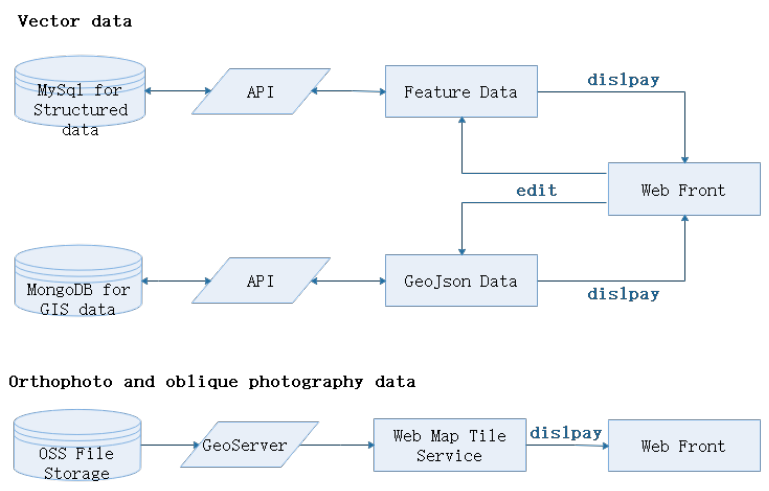

Figure 9. Data Flows of Vector Data, Orthophoto and Oblique Photogrammetry Models.

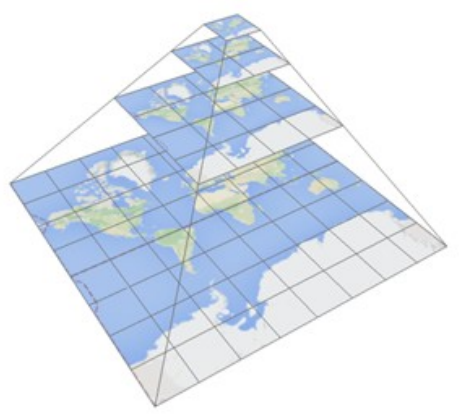

Figure 10. Map Tile Service Diagram.

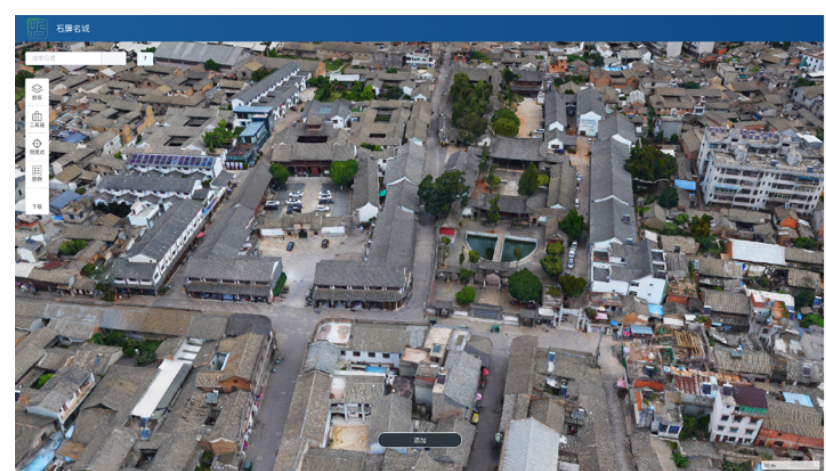

Figure 11. Oblique Photogrammetry Model Display.

4.2.3 Building A Flexible Geo-Spatial Database with A Time Dimension: In MongoDB, each piece of GIS data has a timestamp, which record when the data is modified. It records the attribute and spatial information in different time dimensions, facilitating a dynamic spatial-temporal database.

4.2.4 Ensuring Data Security and Safety: Alibaba Cloud Elastic Compute Service can support data storage and stable computing. Meanwhile, the role-based permission system ensures appropriate permission at the organization and project levels.

\section{APPLICATION CASE STUDIES}

So far, the platform has been implemented in six China's heritage sites of different scales from 3 ha to 100 ha.

Throughout the process, users become more efficient and professional, because the input information is standard, the working environment is collaborative, and the reference information is sufficient. The collected GIS data are standard and meet management needs, so they could provide adequate information and continuously participate in the following management.

In terms of application scenarios, the platform has been applied for diverse collection tasks, such as building inventories to support conservation strategies for historic cities (Figure 12 14), investigating commercial activities to support operation in historic aeras (Figure 15 and 16), evaluating architecture style to guide the construction of space in traditional villages (Figure 17). One example of the collected layers, customized attributes and reference layers are shown in Table 1.

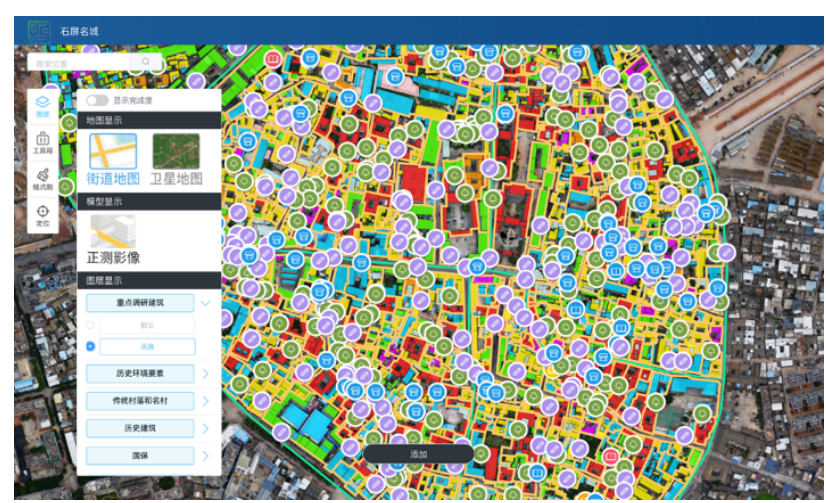

Figure 12. Collection Results of Shiping Historic City.

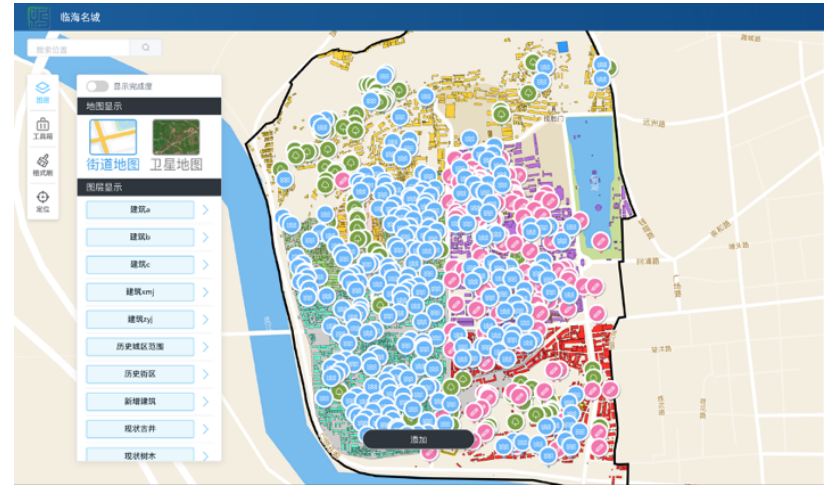

Figure 13. Collection Results of Linhai Historic City.

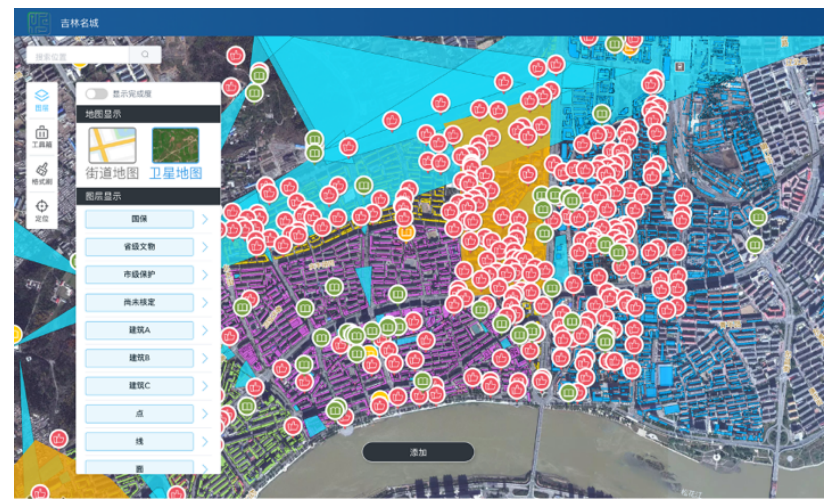

Figure 14. Collection Results of Jilin Historic City. 


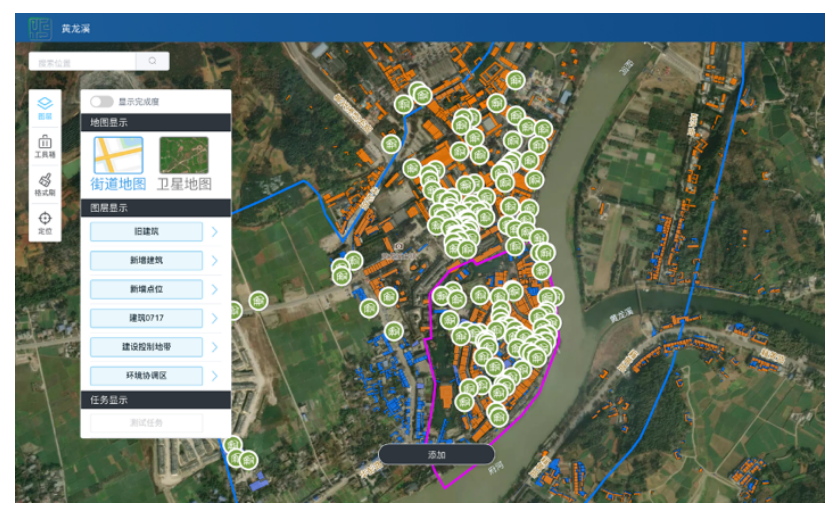

Figure 15. Collection Results of Huanlgongxi Historic Town.

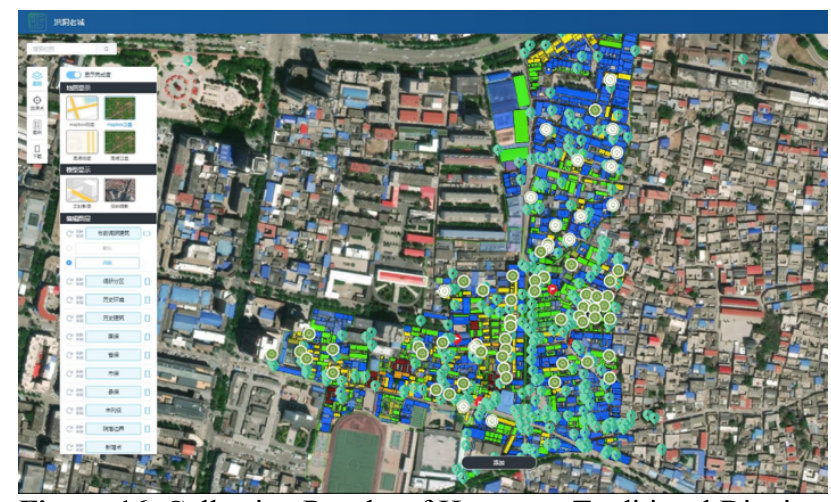

Figure 16. Collection Results of Hongtong Traditional Districts.

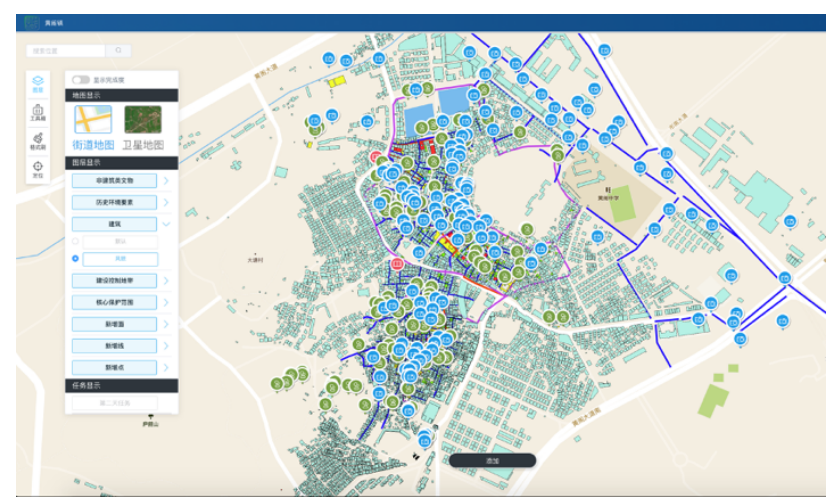

Figure 17. Collection Results of Dajing \& Lianxi Traditional Villages.

\begin{tabular}{|c|c|c|}
\hline $\begin{array}{c}\text { Collected } \\
\text { Layers }\end{array}$ & $\begin{array}{c}\text { Customized } \\
\text { Attributes }\end{array}$ & Field Values \\
\hline \multirow{4}{*}{$\begin{array}{c}\text { Architecture } \\
\text { (polygon) }\end{array}$} & Name & Manually entered \\
\cline { 2 - 3 } & Style & $\begin{array}{c}\text { Selected enter: Ming Dynasty/ } \\
\text { Qing Dynasty/ Before 1949/ } \\
\text { Before 1980s/ After 1980s/ } \\
\text { Unknown }\end{array}$ \\
\cline { 2 - 3 } & & $\begin{array}{c}\text { Immovable historic } \\
\text { monuments and sites/ Historic } \\
\text { building/ Suggested historic } \\
\text { building / Traditional style } \\
\text { building/ Buildings consistent } \\
\text { with traditional styles/ } \\
\text { Buildings consistent with } \\
\text { traditional styles/ Others }\end{array}$ \\
\cline { 2 - 3 } & Class & $\begin{array}{c}\text { national/ Provincial/ City / Not } \\
\text { yet approved/ Unknown } \\
\text { Good/ Medium/ Poor }\end{array}$ \\
\cline { 2 - 3 } & Quality & $1 / 2 / 3 / 4 / 5 / 6 / 7 / 8 />=9$ floors \\
\cline { 2 - 3 } & Height &
\end{tabular}

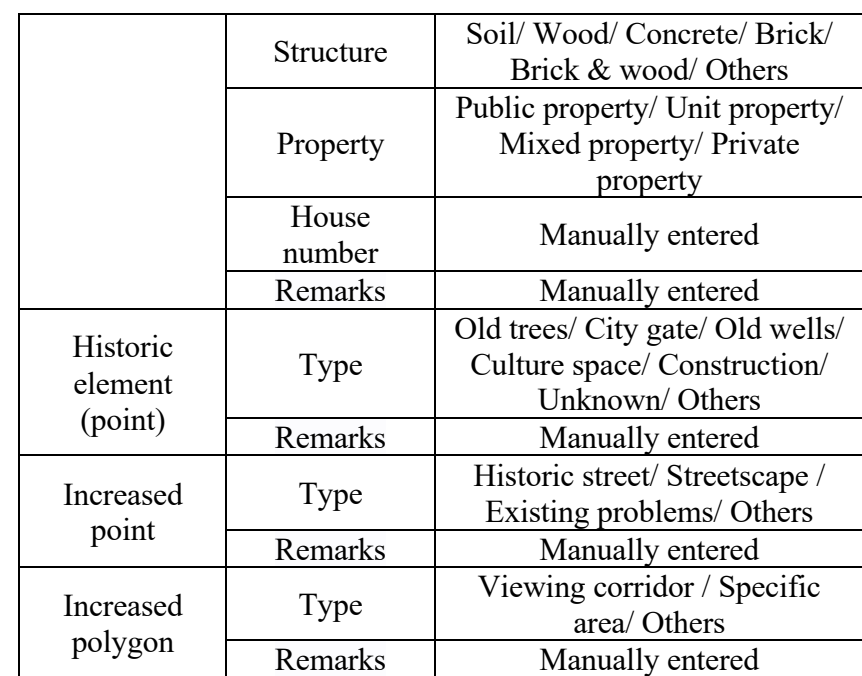

Reference layers: Online base map, Remote sensing images, Oblique Photogrammetry Model, Orthophoto, Related vector GIS layers

Table 1. The Collected GIS Layers, Customized Attributes, Reference Layers, Example of Shiping Historic City.

In terms of efficiency evaluation, these projects accumulated eight types of heritage resources, over 30,000 records of data, over ten dimensions of attributes and related multimedia information. The platform significantly improves data collecting efficiency from an average of 0.5 ha (100 heritage resources) per person per day to 3 ha (600 heritage resources) per day. The efficiency and the size of collected data is shown in Table 2.

\begin{tabular}{|c|c|c|}
\hline Heritage Site & Efficiency & $\begin{array}{c}\text { Size of } \\
\text { Collected Data }\end{array}$ \\
\hline $\begin{array}{l}\text { Huanglongxi } \\
\text { Historic Town }\end{array}$ & $\begin{array}{c}50 \mathrm{ha} / \\
4 \text { persons/ } 5 \text { days }\end{array}$ & $\begin{array}{c}\text { 2G photo files } \\
\& 2,194 \text { GIS data }\end{array}$ \\
\hline $\begin{array}{c}\text { Jilin } \\
\text { Historic City }\end{array}$ & $\begin{array}{c}800 \mathrm{ha} / \\
6 \text { persons/ } 8 \text { days }\end{array}$ & $\begin{array}{l}11 \mathrm{G} \text { photo files } \\
\& 9,928 \text { GIS data }\end{array}$ \\
\hline $\begin{array}{c}\text { Shiping } \\
\text { Historic City }\end{array}$ & $\begin{array}{c}70 \mathrm{ha} / \\
6 \text { persons } / 7 \text { days }\end{array}$ & $\begin{array}{l}\text { 35G photo files } \\
\& 9,753 \text { GIS data }\end{array}$ \\
\hline $\begin{array}{c}\text { Linhai } \\
\text { Historic City }\end{array}$ & $\begin{array}{c}380 \mathrm{ha} / \\
7 \text { persons/ } 6 \text { days }\end{array}$ & $\begin{array}{l}\text { 25G photo files } \\
\& 6,153 \text { GIS data }\end{array}$ \\
\hline $\begin{array}{c}\text { Dajing \& Lianxi } \\
\text { Traditional Villages }\end{array}$ & $\begin{array}{c}10 \mathrm{ha} / \\
3 \text { persons } / 3 \text { days }\end{array}$ & $\begin{array}{l}\text { 18G photo files } \\
\& 3,457 \text { GIS data }\end{array}$ \\
\hline $\begin{array}{c}\text { Hongtong } \\
\text { Traditional Districts }\end{array}$ & $\begin{array}{c}8 \mathrm{ha} / \\
4 \text { persons/ } 3 \text { days }\end{array}$ & $\begin{array}{l}15 \mathrm{G} \text { photo files } \\
\& 3,260 \text { GIS data }\end{array}$ \\
\hline
\end{tabular}

Table 2. The Efficiency and The Size of Collected Data in Six Heritage Sites.

\section{CONCLUSION}

In this paper, we introduce Yingshao, a flexible data collection and management platform for China's heritage sites. Compared with the existing collection methodologies, we aim at collecting vector GIS data and solve the limitations by applying an advanced system framework and data storage schema. There are four aspects of innovations in the platform: establishing a standard and cooperative workflow, integrating diverse data sources, building a flexible geospatial database with a time dimension, and ensuring data security and safety.

Since Yingshao platform has successfully applied to six heritage sites, we believe that it could be a basis for exploring system-level heritage site's digital management mechanism in 
the future. Additionally, it is feasible to authorize data interfaces to the public, academia and enterprises, enabling the dataset to generate greater social and economic values.

\section{REFERENCES}

Aspöck, E., Masur, A., 2015: Digitizing Early Farming Cultures customizing the Arches Heritage Inventory \& Management System. 2015 Digital Heritage, 463-464. doi.org/10.1109/DigitalHeritage.2015.7419549.

Dhonju, H.K., Xiao, W., Mills, J.P., Sarhosis, V., 2018: Share Our Cultural Heritage (SOCH): Worldwide 3D Heritage Reconstruction and Visualization via Web and Mobile GIS. ISPRS International Journal of Geo-Information 7(9), 360. doi.org/10.3390/ijgi7090360.

Dore, C., Murphy, M., 2012: Integration of Historic Building Information Modeling (HBIM) and 3D GIS for recording and managing cultural heritage sites. 18th International Conference on Virtual Systems and Multimedia, 369-376. doi.org/10.1109/VSMM.2012.6365947.

Myers, D., 2016: Heritage inventories: promoting effectiveness as a vital tool for sustainable heritage management. Journal of Cultural Heritage Management and Sustainable Development 6(2), 102-112. doi.org/10.1108/JCHMSD-02-2016-0009.

Myers, D., Dalgity, A., Avramides, I., Wuthrich, D., 2012: Arches: An Open Source GIS for the Inventory and Management of Immovable Cultural Heritage. Progress in Cultural Heritage Preservation 7616, 817-824. doi.org/10.1007/978-3-642-34234-9_87.

Qu, W., Li, M.J., Zhang, X.Q., and Wang, Z., 2019: Management Processes Reconstruction of Historical Buildings Supported by Smart Technology - a Case Study of Fuzhou City. ISPRS - International Archives of the Photogrammetry, Remote Sensing and Spatial Information Sciences XLII-2/W15, 953956. doi.org/10.5194/isprs-archives-XLII-2-W15-953-2019.

Soler, F., Melero, F.J., Luzón, M.J., 2017: A complete 3D information system for cultural heritage documentation. Journal of Cultural Heritage 23, 49-57.

doi.org/10.1016/j.culher.2016.09.008.

Stathopoulou, E. K., Georgopoulos, A., Panagiotopoulos, G., Kaliampakos, D., 2015: Crowdsourcing Lost Cultural Heritage. ISPRS Annals of the Photogrammetry, Remote Sensing and Spatial Information Sciences II-5/W3, 295-300.

Xiao, W., Mills, J., Guidi, G., Rodríguez-Gonzálvez, P., Barsanti, S.G., González-Aguilera, D., 2018: Geoinformatics for the conservation and promotion of cultural heritage in support of the UN Sustainable Development Goals. ISPRS Journal of Photogrammetry and Remote Sensing 142, 389-406. doi.org/10.1016/j.isprsjprs.2018.01.001.

Zerbini, A., 2018: Developing a Heritage Database for the Middle East and North Africa. Journal of Field Archaeology 43, 9-18. doi.org/10.1080/00934690.2018.1514722. 